\title{
Child and Adolescent Psychiatry Fellowship Program Website Content and Accessibility
}

\author{
Simone A. Bernstein ${ }^{1}$ (I) $\cdot$ Alex Gu ${ }^{2} \cdot$ Sophie L. Bernstein ${ }^{3} \cdot{\text { Chapman } W^{2} i^{2} \cdot \text { Alecia C. Vogel }^{1} \cdot \text { Jessica A. Gold }}^{1}$
}

Received: 27 May 2020 / Accepted: 14 January 2021 / Published online: 27 January 2021

(C) Academic Psychiatry 2021

\begin{abstract}
Objective When child and adolescent psychiatry fellowship applicants are applying to programs, many will use fellowship websites to gather information. This study assesses the accessibility and content available on child and adolescent fellowship websites.

Methods Using the Electronic Residency Application Service (ERAS) list of child and adolescent fellowship programs for 2020, 139 child and adolescent fellowship training websites were compiled. Information on websites was evaluated within the following three categories: program overview, application information and recruitment, and educational opportunities. A total of 22 criteria were evaluated within these three categories. Descriptive statistics were used to analyze the websites.

Results A list provided by ERAS and a Google search identified child and adolescent fellowship program websites. Analysis of content revealed most websites included an overview of the program (97.8\%), but fewer included information such as the number of fellowship spots (51.5\%), salary (45.5\%), application deadline (41.0\%), and call responsibility (19.4\%).

Conclusion Results suggest there is room for improvement in the comprehensiveness and accessibility of child and adolescent fellowship websites. Especially during a time when much of the programmatic information will be obtained virtually due to COVID-19, it is critical that fellowship websites are uniformly curated so applicants can more easily find information about programs.
\end{abstract}

Keywords Child and adolescent fellowship $\cdot$ ERAS $\cdot$ Psychiatry residency $\cdot$ Fellowship $\cdot$ Website

There is a shortage of child and adolescent psychiatrists in the USA. In 2019 , there were approximately 8300 child and adolescent psychiatrists, while $16-20 \%$ of all children and adolescents have a psychiatric disturbance [1]. There are also reportedly over 15 million youth and adolescents that would potentially benefit from consultation or treatment from a child and adolescent psychiatrist [1]. As a result, there is a need for more applicants into child and adolescent psychiatry fellowship programs. In psychiatry, child and adolescent fellowships

Simone A. Bernstein

simone.bernstein@wustl.edu

1 Washington University School of Medicine and Barnes-Jewish Hospital, St. Louis, MO, USA

2 George Washington University School of Medicine and Health Sciences, Washington, DC, USA

3 University of Missouri-Kansas City School of Medicine, Kansas City, MO, USA are the most common fellowship and they participate in the Electronic Residency Application Service (ERAS) match [2]. Yet, in 2020, according to the National Resident Matching Program Data (NRMP), the number of applicants per child and adolescent fellowship position was 0.87 , or there were 313 applicants for 360 positions [3]. Instead of being in demand, spots in the fellowship match went unfilled. Child and adolescent psychiatry fellowship programs must increase their presence and desirability, and one way to do this is through their websites.

Besides using websites to learn more about the field overall, in other specialties, websites play a large role in the application process. One study of anesthesia residents reported that 98\% of applicants used fellowship program websites and 56\% said the content led to decisions about applying to a program [4]. In a survey of interventional radiology program applicants, applicants were most interested in the following website content: didactics, facilities information, rotation schedule, a list of current fellows, and research opportunities for their decision making [5]. 
To our knowledge, child and adolescent psychiatry program websites have not been evaluated for content, accessibility, and consistency. Prior studies of other residency and fellowship websites demonstrated deficiencies [6-12]. Evaluating the utility of websites is particularly important given the impact of the COVID-19 pandemic on the application process. In May 2020, the Association of American Medical Colleges (AAMC) strongly encouraged medical school and teaching hospital faculty to conduct all interviews virtually [13]. This made recruitment more challenging for fellowship programs and increased the importance of their online presence.

This study aims to evaluate the fellowship websites of child and adolescent training programs, where residents complete 2 years of child and adolescent psychiatry training after completing 3 or 4 years of general psychiatry training. As previous research in other fields has shown websites are not comprehensive, we hypothesize that child and psychiatry fellowship websites will lack content, accessibility, and consistency.

\section{Methods}

The American Academy of Child and Adolescent Psychiatry (AACAP) has a list of the Accreditation Council for Graduate Medical Education (ACGME) accredited programs, but the list was inactive at the time the data was collected in April 2020. As such, child and adolescent fellowship programs were identified from a list provided by ERAS. In total, 139 child and adolescent fellowship programs were identified. Integrated programs, where applicants apply to a combined psychiatry residency and child and adolescent fellowship as medical students, were excluded.

In order to determine user accessibility, each fellowship website was located two ways, via ERAS and the Google search engine. Using Google, a search was performed using ["program name" and "child and adolescent psychiatry fellowship"]. When the fellowship website was located, the number of clicks was recorded to get to the introductory page.

Information obtained from the fellowship websites was evaluated with the following three categories: program overview, application process/recruitment, and education. The first category, program overview, included the program description, address, phone number, the program director's name, accreditation status and accreditation year, a list of current fellows, a list of prior fellows, and their employment locations. A second category, application information and recruitment, included application requirements, application deadline, and salary. The third category, education, included didactic sessions, rotation schedules, call requirements, research opportunities, examples of research projects, and a list of faculty.

Two authors verified the data. If there was a dispute between the two authors, a third author was consulted to determine the validity of the information.

\section{Results}

Of the 139 programs located on the ERAS site, 111 (79.9\%) had a link listed to the program website. Of the website links, 45 $(40.5 \%)$ were direct links to the page, $40(36.0 \%)$ were indirect links, and $26(23.4 \%)$ of the links were non-functional (reached an error page). The fellowship websites were also obtained via a Google search. The average number of site clicks required to reach the fellowship homepage from Google was 1.16. Of the 139 programs, $134(96.4 \%)$ had a website.

For the program overview category, almost all programs included a description of their program, 131 (97.8\%), and address, $133(99.3 \%)$. Accreditation status was on 69 $(51.5 \%)$ and only $9(6.9 \%)$ listed their accreditation year. The names of current fellows were on 84 (62.7\%), past fellows on $27(20.1 \%)$, and the current employer of program alumni on $14(10.4 \%)$ websites.

For application information and recruitment, only 69 $(51.5 \%)$ listed the number of fellowship spots. Application requirements were listed on $94(70.1 \%)$, instructions on how to apply on $114(85.1 \%)$, and a deadline for submission of materials on $55(41.0 \%)$ websites. Benefits (salary) were found on $61(45.5 \%)$ websites.

For educational opportunities, rotation schedules were on 103 (76.9\%) websites. Didactics were on 105 (78.4\%), 65 (48.5\%) provided information about journal club, 89 (66.4\%) had research opportunities, and 28 (20.9\%) websites included examples of research projects. Only $26(19.4 \%)$ discussed the call schedule and/or responsibility of a trainee. Names of child and adolescent faculty were on 109 (81.3\%) websites.

\section{Discussion}

The results of this study support the hypothesis that while basic information about child and adolescent psychiatry programs is available with individual searching effort, the content, accessibility, and consistency of child and adolescent websites can be improved. Obtaining information about fellowship programs is a key part of the application process, especially for those seeking to pursue fellowship at a different institution or who do not have access to a fellowship at their residency institution. The data found is the key to comparing programs and ranking them successfully, particularly in a post-COVID-19 world where interviews are virtual and campus visits no longer occur.

For program overview, almost all of the evaluated websites included information about program details; however, few had information about current fellows, past fellows, and current employers of alumni. Showcasing the diversity of a program could be the key for an applicant. In a study of ophthalmology residency applicants, females and ethnic minorities were found to place significant importance on the gender 
and ethnic diversity of faculty and trainees [14]. While the most significant barrier to including the names of current fellows, past fellows, and employers of alumni is that websites need to be frequently updated, even just spotlighting a segment of alumni could help promote the success of program graduates and provide applicants an opportunity to learn about diverse aspects of the program. Since applicants will interact with fewer fellows through virtual interviewing, learning more about them through the website is also key.

For application information and recruitment, one of the most important features of a good website is convenience. A person should not have to click back onto ERAS to find information and anything an applicant would be interested in comparing between programs should be easily located on each program's site. However, even if applicants were interested in submitting a fellowship application, there was only sufficient information about an application timeline on less than half of the websites. Without a timeline, all of the information needed is not easily accessible in one place. In particular, this hinders those who develop an interest in the field later during the applications cycle as some programs will complete their review cycle earlier in the year. Additionally, benefits like salary were listed by only half of the programs. According to Per et al. supportive benefits are positive determinants of job satisfaction [15]. Since child and adolescent fellows choose to invest in additional education rather than complete an adult psychiatry residency to start a higher salary job, benefits including health insurance coverage and childcare could play a significant role in choosing a program. This would be particularly important if there are significant differences or cost of living factors to include in calculations. Including a link to the graduate medical education website would provide the most updated benefits.

In regard to educational opportunities, applicants often turn to websites to learn about educational opportunities at programs and this is only magnified when they are not interviewing in person. One of the educational factors analyzed was whether the websites showed research opportunities and examples of projects. This information is a way for applicants to gauge whether they could get involved similarly as a fellow. By including examples of past poster presentations, publications, and conference talks, applicants with academic psychiatry career goals may be particularly drawn to a program. Providing specific examples of research also allows applicants to see the potential for mentorship, as mentors can be important in a trainee's future career [16].

Few programs provided specific information about the call schedule. Incorporating call schedule requirements into a website is important, as psychiatric trainees were more likely to stress expectation of working hours being more compatible with family life as an important factor in their career selection [17]. Adding this information to a website would give applicants an understanding of their potential work-life balance. While call schedules can be malleable depending on circumstances like maternity leave, posting approximate schedules can help in decision making. Although there might be hesitation from programs with heavier requirements to post their schedules, programs should be clear about their requirements up front to find the most interested and compatible applicants.

Our findings are consistent with graduate medical education website studies in other fields, suggesting the need for consistency and improvement. In a study of orthopedic surgery arthroplasty websites, content and accessibility were found to lack relevant information [12], and in response, the American Association of Hip and Knee Surgery called on their fellowship programs to make improvements to websites [18]. In order to improve fellowship websites long-term, it would be beneficial if the AACAP created a list of minimal website recommendations so programs could update their sites more uniformly and applicants could then compare programs more easily. Table 1 includes the website categories where the majority of child and adolescent fellowships did not include the information and would benefit from updates.

While the number of applications to general psychiatry training programs has increased, the number of fellowship applicants has not seen similar improvements [19]. In order to encourage applicants to apply to fellowships, and see the value of it, information about programs and the field needs to be easily and readily accessible. This way, if a psychiatry resident is interested in a fellowship in general, or a specific program, they could learn more. Websites are under direct control of the program so they are more accurate than other sites like blogs, Doximity, or Residency Explorer. When it
Table 1 Categories of information found in less than $50.0 \%$ of evaluated websites

\begin{tabular}{lll}
\hline Categories & Number of websites & Percent of evaluated websites (\%) \\
\hline Accreditation year & 9 & 6.9 \\
Current employer of program alumni & 14 & 10.4 \\
Call schedule & 26 & 19.4 \\
Names of past fellows & 27 & 20.1 \\
Examples of research projects & 28 & 20.9 \\
Application deadline & 55 & 41.0 \\
Benefits (salary) & 61 & 45.5 \\
Journal club & 65 & 48.5 \\
\hline
\end{tabular}


comes to actually applying, while reputation and word of mouth are also important in the decision-making process, for those residents who have less exposure to the field or do not have a fellowship program at their home institution, websites are likely to play an important role. That role is only magnified with virtual interviews as many fellowship applicants will not visit the programs that they are applying to. As such, it will also be important to update sites with the basics and consider including video tours of clinical spaces, interviews with residents and faculty, and social media links on websites [20].

Limitations to this study include the lack of a comprehensive list of what applicants might be interested in on fellowship websites. For example, elective rotations were excluded. While there were two evaluators to cross-reference information on websites, each feature is subject to evaluator bias and could be further decreased with a third reviewer. The data was collected during a period of time in April 2020. Thus, if the AACAP, ERAS, or program websites updated websites after this time period, this information would not be included in these results. Also, not all programs use ERAS, so there were likely other fellowship programs that were not evaluated. Additionally, all information was gathered using a program's fellowship website, while there might be additional information about a program in other places.

In conclusion, the results of this study suggest that there is room for improvement in the comprehensiveness and consistency of child and adolescent psychiatry fellowship websites. Given virtual interviews due to COVID-19 and the need for more child and adolescent psychiatrists, it is critical that fellowship websites are uniformly updated so applicants can more easily find information. Directly assessing applicants' report of what factors were important in choosing to apply to fellowship at all, where to submit an application, and if applications increase with website improvement are important future directions. Future studies should highlight the experience of trainees as they explore these fellowship websites and the importance of various factors to aid their decision-making.

\section{Compliance with Ethical Standards}

Disclosures The authors of this paper have no disclosures to report.

\section{References}

1. American Academy of Child and Adolescent Psychiatry (AACAP). Workforce issues. Available from: https://www.aacap.org/ AACAP/Resources_for_Primary_Care/Workforce_Issues.aspx [Accessed 01 May 2020].

2. American Academy of Child and Adolescent Psychiatry (AACAP). Choosing child and adolescent psychiatry as a career. Available from: https://www.aacap.org/AACAP/Medical_Students_and
Residents/Medical_Students/Choosing_CAP_as_a_Career.aspx\# eight [Accessed 05 May 2020].

3. National Resident Matching Program. Results and Data Specialties Matching Service, 2020 Appointment Year. https:// mk0nrmp3oyqui6wqfm.kinstacdn.com/wp-content/uploads/2020/ 02/Results-and-Data-SMS-2020.pdf [Accessed 5 May 2020].

4. Chu LF, Young CA, Zamora AK, Lowe D, Hoang DB, Pearl RG, et al. Self-reported information needs of anesthesia residency applicants and analysis of applicant-related web sites resources at 131 United States training programs. Anesth Analg. 2011;112(2):430-9.

5. Charalel RA, Pua BB, Galla N, Trehan SK, Madoff DC. Interventional radiology fellowship website content: what is the relevance to potential applicants? Clin Imaging. 2016;40(6): 1070-4.

6. Hansberry DR, Bornstein J, Agarwal N, McClure KE, Deshmukh SP, Long S. An assessment of radiology residency program websites. J Am Coll Radiol. 2018;15(4):663-6.

7. Hashmi A, Policherla R, Campbell H, Khan FA, Schumaier A, AlMufarrej F. How informative are the plastic surgery residency websites to prospective applicants? J Surg Educ. 2017;74(1):74-8.

8. Ashack KA, Burton KA, Soh JM, Lanoue J, Boyd AH, Milford EE, et al. Evaluating dermatology residency program websites. Dermatol Online J. 2016;22(3):13030/qt7rx3j2dn.

9. Stoeger SM, Freeman H, Bitter B, Helmer SD, Reyes J, Vincent $\mathrm{KB}$. Evaluation of general surgery residency program websites. Am J Surg. 2019;217(4):794-9.

10. Ruddell JH, Eltorai AEM, Bakhit M, Lateef AM, Moss SF Analysis of accredited gastroenterology fellowship internetavailable content: twenty-nine steps toward a better program website. Dig Dis Sci. 2019;64(5):1074-8.

11. Huang BY, Hicks TD, Haidar GM, Pounds LL, Davies MG. An evaluation of the availability, accessibility, and quality of online content of vascular surgery training program websites for residency and fellowship applicants. J Vasc Surg. 2017;66(6):1892-901.

12. Gu A, Lehman JD, Sardana A, Cohen JS, Richardson SS, Sculco PK. Adult reconstruction hip and knee fellowship program content and accessibility. J Arthroplast. 2018;33(6):1630-3.

13. The Association of American Medical Colleges. Conducting interviews during coronavirus pandemic. Available from: https://www. aamc.org/what-we-do/mission-areas/medical-education/ conducting-interviews-during-coronavirus-pandemic. [Accessed 07 May 2020].

14. Yousuf SJ, Kwagyan J, Jones LS. Applicants' choice of an ophthalmology residency program. Ophthalmology. 2013;120(2):423-7.

15. Artz B. Fringe benefits and job satisfaction. Int J Manpow. 2010;31:626-44.

16. Burgess A, van Diggele C, Mellis C. Mentorship in the health professions: a review. Clin Teach. 2018;15(3):197-202.

17. Wiesenfeld L, Abbey S, Takahashi SG, Abrahams C. Choosing psychiatry as a career: motivators and deterrents at a critical decision-making juncture. Can J Psychiatr. 2014;59(8):450-4.

18. Krebs VE, Mont MA, Backstein DJ, Mason JB, Taunton MJ, Froimson MI, et al. A call to upgrade our adult reconstruction fellowship websites! J Arthroplasty. 2018;33(6):1629.

19. National Resident Matching Program ${ }^{\circledR}$ : Results and data: Specialties Matching Service 2008-2017. Available at: http:// www.nrmp.org/report-archives. Accessed December 1, 2020.

20. Bernstein S, Gu A, Chretien K, Gold J. Graduate medical education virtual interviews and recruitment in the era of COVID-19. J Grad Med Educ. 2020;12(5):557-60.

Publisher's Note Springer Nature remains neutral with regard to jurisdictional claims in published maps and institutional affiliations. 